\title{
Santa Rosa de Lima y Descartes
}

\author{
Jorge SECADA
}

\section{RESUMEN}

Comparando las vías hacia la contemplación y el amor de Dios del meditador de las Meditaciones de Descartes y de la santa limeña, el artículo revela una dimensión central pero no reconocida de la obra del filósofo francés, lo que le permite al autor articular interesantes problemas relativos a la concepción misma de la filosofía y a las relaciones entre conocimiento, entendimiento y vida.

Palabras clave: Descartes, metafísica, mística, platonismo, Santa Rosa de Lima

\section{Abstract}

Through a comparison between the roads to the contemplation and love of God of the cartesian meditator and of Saint Rose of Lima, the paper reveals an essential but ignored aspect of Descartes's Meditations on First Philosophy. This leads the author to the formulation of interesting problems relating to the very 
nature of philosophy and the relations between knowledge, understanding, and life.

KeYwords: Descartes, metaphysics, mysticism, Platonism, Saint Rose of Lima

Isabel Flores de Oliva, santa Rosa, nació y murió en Lima, en 1586 y 1617 . Fue contemporánea de Descartes, quien vivió, principalmente en Francia y Holanda, entre 1596 y 1650. Ambos cruzaron, pues, el umbral que solemos usar para designar el inicio de la llamada edad moderna. Pero ¿qué más los relaciona y qué relevancia puede tener esta coincidencia en el tiempo? ¿Qué justifica, en otras palabras, el título de este ensayo?

La tesis que sostendré es que bastante más los une y es de considerable importancia para la comprensión del pensamiento del gran filósofo. Nuestra visión de la obra cartesiana se filtra por los valores de la Ilustración, valores que informan el horizonte desde el cual naturalmente la interpretamos. El Descartes de nuestros tiempos es, digamos, kantiano. Puesto en estos términos, sostendré que, si de su significado histórico se trata, su obra metafísica está más cerca de la santa limeña que del idealista alemán. Tanto él como santa Rosa son expresiones de la reforma católica renacentista, dos caras de la renovación espiritual del siglo XVI, ancladas ambas en la tradición mística de san Agustín (354-430) y san Francisco de Asís ( 1182-1226), san Buenaventura ( 1221-1274), santa Teresa de Jesús (1515-1582), san Juan de la Cruz (1542-1591) y san Francisco de Sales (1567-1622). Sostendré, igualmente, que relacionar al francés con la limeña nos permite abordar temas y aspectos de su obra maestra, las Meditaciones de filosofía primera, que hemos perdido de vista. Esta ceguera impide la comprensión del texto mismo, lo distorsiona y genera insolubles problemas que consumen mucho de los estudios cartesianos hoy en día. Al recobrar el sentido original de las Meditaciones, también revelamos un tesoro de problemas que 
están en el centro mismo de la metafísica y la filosofía y cuya ausencia empobrece buena parte del pensamiento contemporáneo.

Sobre santa Rosa no tengo nada original ni propio que ofrecer. Empezaré, por consiguiente, con una breve sección que no tiene otro propósito que resumir, siguiendo a otros autores, los aspectos de su vida y obra que nos importan. En las siguientes tres secciones articularé mi tesis demostrando primero que, en efecto, las Meditaciones son un manual para la meditación sobre Dios y sobre mí mismo y no un ensayo o un tratado académico de filosofía, explicando luego cómo debemos entender la meditación metafísica cartesiana y qué es para Descartes el amor de Dios al cual conduce. Después, en la cuarta sección, mostraré que un contexto esencial para su lectura es el de la tradición mística cristiana a la cual ya he aludido. En la quinta, veremos cómo la comparación con santa Rosa, que la sección anterior invita, nos permite plantear un cuerpo de problemas en el centro mismo del pensamiento filosófico. Cierro el artículo con una breve reformulación del camino andado, a modo de conclusión.

\section{Santa Rosa y El AMOR DE Dios}

La corta vida de santa Rosa expresa plenamente y con asombrosa coherencia la espiritualidad que encontramos elaborada en detalle en la obra de, por ejemplo, santa Catalina de Siena (13471380) o santa Teresa de Jesús. ${ }^{1}$ Es una vida íntegramente dedicada al amor de Dios.

1 Ver José Antonio del Busto Duthurburu (2006) y Ramón Mujica (2005: 45260). También los capítulos de R. Mujica, y de Luis Eduardo Wufarden y Pedro Guibovich, en José Flores Araoz et al. (1995: 3-211) y la cuidada edición de sus pocos escritos conservados, con un detallado estudio y comentario, en Rosa Carrasco Ligarda (2016). 
José Antonio del Busto, en su cuidadosa biografía, nos dice que «[e]l objetivo supremo, para Rosa, siempre fue Dios. Todo lo demás era efímero y superfluo... [D]escubrió a Dios siendo muy niña... Creyó siempre en el amor a Dios» (2006: 90). ${ }^{2}$ Solía decir, según un testigo, que quienes no aman a Dios «no saben lo mucho que merece ser amado». ${ }^{3}$ Otro testigo, que la interrogó largamente, reporta que «su entendimiento todo estaba ocupado en abrazar a Dios» y que ella «deseaba en gran manera conocer a su Dios para amarle». ${ }^{4}$ Como se desprende de lo que sabemos, toda su vida estuvo informada por el amor de Dios. Pero ¿qué significa amar a Dios como lo amó santa Rosa?

Podemos resumir este amor de Dios, que invadió la totalidad de su persona y sus actos, es decir, todo lo que hacía y pensaba, día y noche, prácticamente desde que empezó a tener consciencia y autonomía, como el despliegue, el desarrollo y ejercicio, de un conjunto de virtudes, hábitos o disposiciones, todas dirigidas consciente y explícitamente, a buscarlo, obedecerlo, honrarlo y unirse a Él.

Cristo condensa su mensaje en dos mandamientos:

uno... le preguntó...: Maestro, ¿cuál es el mandamiento mayor de la Ley? Él le dijo: Amarás al Señor tu Dios con todo tu corazón, con toda tu alma y con toda tu mente. Este es el mayor

2 En lo que sigue me baso en la biografía de Del Busto como fuente para los detalles y hechos de la vida de Santa Rosa, sin considerar necesario dar referencias en cada instancia. El libro de Del Busto sirve de complemento y correctivo a la mención en la importante historia de Bernard McGinn (2017), siendo la biografía de Del Busto un trabajo estrictamente histórico y no especulativo como los de Frank Graziano (2004) y Kathleen Ann Myers (2003), las únicas fuentes modernas citadas por McGinn aparte de la hagiografía de Hansen (1664); ver Bernard McGinn (2017: 395-396 y 433) y José Antonio del Busto Duthurburu (2006: 15-17).

3 Lo señala fray Luis de Bilbao, confesor de la santa durante la última mitad de su vida, citado en José Antonio del Busto Duthurburu (2006: 91).

4 Testimonio de Juan del Castillo en José Antonio del Busto Duthurburu (2006: 180-181). 
y primer mandamiento. El segundo es semejante a éste: Amarás a tu prójimo como a ti mismo. De estos mandamientos [pende] toda la Ley. ${ }^{5}$

Los dos mandamientos son inseparables. Esto queda claro en el evangelio de san Juan y en su primera epístola:

amémonos unos a otros, porque el amor es de Dios, y todo el que ama ha nacido de Dios y conoce a Dios. Quien no ama no ha conocido a Dios, porque Dios es Amor. En esto se manifestó entre nosotros el amor de Dios; en que Dios envió al mundo a su Hijo único... como víctima de expiación por nuestros pecados... A Dios nadie lo ha visto nunca. Si nos amamos unos a otros, Dios mora en nosotros... [Q]uien no ama a su hermano, a quien ve, no puede amar a Dios a quien no ve. Y nosotros hemos recibido de él este mandamiento: quien ama a Dios, ame también a su hermano. ${ }^{6}$

Amar a Dios es amarse a uno mismo y al prójimo, que no es sino cualquier ser humano con el que tengamos relación. Amar a Dios por sobre todo es vivir plenamente poseído por Él y para Él.

La fe de Rosa es segura. No es una mera creencia, ni siquiera una convicción. Se trata de una parte esencial de su persona, presente en toda su conducta, una verdadera virtud, al igual que su esperanza y su caridad. Y por ello despliega tenazmente y sin excepción también prudencia y amor propio, obediencia a sus padres y sus directores espirituales y consejeros, modestia y humildad, y justicia y generosidad para quienes cruzaron su camino. Crucialmente, desarrolla una fortaleza y templanza admirables, que le permiten persistir sin desviarse nunca en la práctica de esas otras virtudes.

Según la perspectiva cristiana, la condición humana es la de un espíritu encarnado, es decir, la de una entidad entre dos mundos. Vivimos corporalmente. Pero nuestra finalidad última, nuestra

5 San Mateo 22, 34-40. Ver San Lucas 10, 25-28; San Marcos 12, 28-31; y también Deuteronomio 6, 1-6.

6 Primera Epístola de San Juan, 4, 7-21. Ver también San Juan 13, 34-35. 
plenitud, no es meramente corporal. Aquí debemos capturar un balance delicado. El cuerpo, en sí mismo, es nada y nos aleja de Dios. Pero el cuerpo no es en verdad nada porque es y está conservado en todo momento por Dios mismo. Encontrar su real valor es encontrar en él la imagen de Dios. Este punto, de suma importancia, está presente en la obra de san Buenaventura, para mencionar a una de las figuras centrales en la tradición espiritual que nos interesa, que en esto sigue los pasos de san Francisco, fundador de su orden. ${ }^{7}$ Encontrar a Dios, que no es de este mundo, en el mundo, que es imagen suya, requiere una disciplina particular.

El cuerpo se manifiesta en nosotros a través de apetitos. El apetito, como uso los términos aquí, no agota el deseo. No solo eso, sino que apetito y deseo son fenómenos diversos. ${ }^{8} \mathrm{El}$ primero está dirigido a la posesión de su objeto, a la transformación del mundo para aquietarse. Queremos comer una chirimoya; buscamos cambiar el mundo para que sea verdad que la comemos. La bondad y el valor del objeto apetitivo depende del apetito: la chirimoya es sabrosa y valiosa en cuanto la apetecemos; no lo es para quien no la apetece. El placer que obtenemos con la satisfacción de los apetitos es corporal y pasajero. Y típicamente tiene un límite que exploramos pagando un precio con hartazgo, descontento y hasta dolor.

El valor del objeto de deseo, por otro lado, no depende de nosotros ni de nuestras inclinaciones, sino que estas más bien lo presuponen. Deseamos la música porque es buena, y quien no la desea es, en esa medida, sordo. Lejos de poseer y agotar sus objetos, el deseo busca someterse a ellos, adquirir la disciplina necesaria para descubrirlos y apreciarlos. Mientras el apetito busca transformar el mundo, el deseo busca transformar a quien lo posee, para que la bondad de su objeto lo enriquezca.

7 Ver san Buenaventura (2010) y se pueden consultar también las obras de san Francisco de Asís (2006).

8 Ver Jorge Secada (2013) y Tal Brewer (2009). 
Aunque tendremos ocasión de volver sobre este asunto, este no es el lugar para establecer la distinción, desarrollarla y explorar la compleja estructura de apetito y deseo que articula la vida plena. Mi propósito es usar estas categorías para entender un aspecto de la vida de santa Rosa: su ascetismo y su disciplina corporal. Dormir sobre una cruz, usar cilicio, alimentarse con frugalidad extrema, mortificar el cuerpo en grado sumo y extraordinario, como sabemos que hizo, son las prácticas con que desarrolló su templanza y ordenó sus apetitos para ponerlos todos al servicio del deseo y amor de Dios. Asimismo, más allá de su oración y culto explícitos, sus obras de caridad, su vida familiar, su aprecio de la naturaleza, su canto y alegría, fueron oportunidades para encausar toda su existencia al amor de Dios. Es evidente, entonces, que los milagros y los raptos místicos, en cuanto los hubo, no fueron sino momentos particulares y discretos de lo que fue una vida constantemente poseída por el amor de Dios. Semejante disciplina de vida, requiere atención y práctica constante, toda un vida en efecto, y no es asunto de raptos ni experiencias discretas.

En esto santa Rosa ejemplifica lo que otro contemporáneo suyo, san Francisco de Sales, captura en sus obras, la Iniciación a la vida devota de 1609 y el Tratado del amor de Dios de 1616. Más adelante examinaremos nuevamente a este autor y estos temas; ahora bastará con resumir el contenido de la primera obra. Ahí nos dice que la «devoción verdadera y viva... no es otra cosa que un verdadero amor de Dios» (2010-2016, I: 16). ${ }^{9}$ Pero la vida devota no es cuestión de simples buenas acciones, ni siquiera cuando se hacen con regularidad y buen ánimo, puesto que presupone purificar al alma de pecado y esto a su vez presupone no solamente meditación sostenida y oración constante sino el desarrollo de una disciplina que

9 El texto citado ha sido cotejado con el original francés de san Francisco de Sales (1819: 3). En las citas de esta obra se indica la paginación en ambas ediciones. En algunas pocas ocasiones he alterado la traducción castellana ligeramente. 
invade todos los aspectos y momentos de la existencia de la persona devota. Su vida incorpora no solamente las prácticas religiosas, sino que está toda ella estructurada por la búsqueda de Dios.

Como mero ejemplo, mencionaremos un pasaje del libro de san Francisco: «Buscar conversaciones y evitarlas son extremos vituperables de la vida en sociedad. Evitarlas supone desdén y menosprecio al prójimo; buscarlas conduce a la ociosidad y a la pérdida de tiempo» (2010-2016, I: 162; y 1819: 241). Lo que sigue es un examen de los diversos tipos de conversación, las que deben evitarse, las que aceptamos «con toda modestia, evitando libertades y ligerezas», y las que buscamos porque contribuyen al desarrollo de nuestras virtudes (2010-2016, I: 163-164; y 1819: 243). San Francisco habla también de la soledad, como complemento necesario de las buenas relaciones, tanto la «soledad mental, a la que puedes retirarte aun en medio de las mayores conversaciones... [como] la soledad local y real... en tu habitación, en el jardín o en sitios semejantes donde con mayor sosiego puedes retirar tu espíritu en tu corazón y recrear tu alma con buenos pensamientos y santos deseos o por medio de algo de buena lectura» (2010-2016, I: 164; y 1819: 244). Vemos, pues, que el amor de Dios invade todo aspecto y todo momento de la vida.

Conviene subrayar que para la santa limeña este amor no es asunto propiamente de mera doctrina. Sin negarla, es el resultado de una fe que más que en el entendimiento habita en el corazón y se manifiesta no en discurso sino en proceder cotidiano. Es una pasión constante que posee el alma toda y que ha puesto al cuerpo a su servicio. En uno de su poquísimos escritos conservados dice:

Dios con lanza de acero me hirió.... El campo del corazón lo llenó Dios de suave amor, haciendo morada de él.... Corazón lleno del divino amor, ... escribe fuera de sí. Corazón traspasado con rayo de amor de Dios. Corazón herido con flecha de divino amor... Llagado corazón con fuego del amor de Dios en cuya fragua se labró; sólo sana quien lo labró con amor. Enferma 
estoy de amores o fiebre que muero de ella.... O dulce martirio que con arpón de fuego me ha herido. Corazón herido con dardo de amor divino da voces por quien lo hirió. Purifica mi corazón; recibe centella de amor para amar a su creador. ${ }^{10}$

En conclusión, para santa Rosa, el amor de Dios no es un rapto, aunque despierte pasión, sino un estado permanente, que se alimenta y a su vez nutre la práctica constante de virtudes que buscan a Dios y llevan a él, y que informa su vida íntegra. La pregunta para nosotros ahora, entonces, es qué tiene esto que ver con las Meditaciones de Descartes. La respuesta, que articularé en la siguiente sección, es que mucho o todo. Dicho sucintamente, el amor de Dios es un objetivo central de esa obra.

\section{¿Qué son las Meditaciones de Descartes?}

Empecemos con una pregunta en apariencia simple pero en realidad, como veremos, compleja e impregnada de sentido: ¿qué son las Meditaciones?

La primera respuesta es que se trata de un libro de filosofía o, más específicamente, de metafísica y epistemología. Esto parece claramente verdadero, pero al examinarlo veremos que dista de ser claro, puesto que los libros de filosofía ocupan una gama muy amplia y difieren entre sí tanto como un poema, una colección de ensayos breves, un tratado sostenido y una lista de aforismos.

Podría alegarse que más allá de su género literario o su forma, los escritos propiamente filosóficos tienen como rasgo común proponer tesis y establecerlas con argumentos racionales. Concedámos-

10 Carrasco Ligarda (2016: 18-26). He modernizado la ortografía e introducido signos de puntuación. En el texto original estas frases están distribuídas en dos caras de una hoja, en torno a corazones, cruces y una escala. Ver la imagen de la hoja en Carrasco Ligarda (2016: 19-20). 
lo. Aun así, parece que esto no resuelve el problema. Consideremos el Poema de Parménides. ${ }^{11}$ Ciertamente, en él podemos encontrar tesis y argumentos, pero ¿cómo han de tomarse? Su proemio nos dice que se trata de revelaciones divinas. $\mathrm{Al}$ considerar nuestra pregunta, no podemos ab initio dejar de lado esta afirmación. La forma poética en que se expresa esa revelación oscura-que el ser es y el no ser no es- puede ser relevante para descubrir su intención y cómo ha de tomarse, es decir, su significado. Sostener sin argumento que el proemio es meramente retórico corre el riesgo de perder de vista lo que Parménides tenga que decir respecto de la naturaleza de la filosofía y su lugar entre los quehaceres humanos.

Pero vayamos a un caso medular. Platón solamente escribió obras en las cuales nunca habla en voz propia, declarativa y directa. Muchos de sus escritos son verdaderos diálogos, en los cuales Platón cuidadosa y detalladamente describe lugares, contextos, circunstancias. Muchos diálogos son aporéticos, sin llegar a resolver la cuestión que los ocupa. Y muchas veces, cuando algún personaje afirma doctrinas declarativamente, lo hace recurriendo a mitos y leyendas, incluso cuando poco antes ha descartado una interpretación literal de otra de ellas y ofrecido en su lugar una interpretación llanamente sensata. ¿Cómo entender todo esto?

Es difícil atribuirle opiniones al autor de un escrito en el que no tiene una voz directa y propia, aunque se pueda especular con mayor o menor base sobre cuáles sean. Y las creencias del autor se pueden inferir con fundamento de lo que un diálogo muestra, más allá de lo que diga explícitamente alguno de sus personajes. Los diálogos inconclusos y aporéticos pueden haber buscado algo que no consiste en responder a sus preguntas manifiestas. En cualquier caso, estas obras nos conducen a preguntar por qué mostrar en lugar de decir. Y como leer las obras de Platón no es cosa sencilla y su resolución toca preguntas relativas a la naturaleza de la filosofía que la referencia a meros argumentos y tesis no responde.

11 Ver Parménides (1965, 2007 y 2011). 
Tal vez los escritos de Platón manifiestan la noción de que, más que un cuerpo de doctrina, la filosofía es una actividad que lleva a una comprensión que no se captura discursivamente, y lo que buscan es inducir al lector a practicarla. Esto es compatible con que los argumentos racionales y las tesis proposicionales tengan un lugar en la práctica filosófica, tal vez uno esencial, pero desde el punto de vista de nuestro interés aquí y ahora, señala en dirección de una respuesta bastante más compleja a nuestra pregunta que la simple afirmación de que se trata de un libro de filosofía del cual debemos extraer doctrinas y argumentos, y sugiere además que el género literario o la forma de un escrito filosófico puede esconder opiniones sustantivas sobre la naturaleza de su disciplina, opiniones relevantes cuando se trata de decidir cómo deba leerse.

Retornemos a nuestra pregunta. ¿Qué es esta obra maestra de la filosofía moderna, las Meditaciones de filosofía primera? ¿No se trata de un ensayo como tantos otros en la historia de la filosofía medieval, moderna y contemporánea? ¿No es acaso un vehículo para la presentación de tesis filosóficas discursivas y argumentos racionales? La respuesta simple es no, no lo es. ${ }^{12}$

Como los diálogos platónicos, las Meditaciones abundan en signos de que no deben abordarse como abordamos un ensayo filosófico. Para comenzar, están escritas en primera persona, extraña elección si de semejante escrito se trata. Ocasionalmente, un autor puede recurrir a la primera persona para tomar distancia frente a lo que afirma, enfatizando que es él quien lo sostiene, pero su uso como norma en todo el escrito requiere alguna explicación.

12 Lo que sigue en esta y las siguientes dos secciones resume conclusiones que he articulado y defendido en mayor detalle en Jorge Secada (2013), en la conferencia plenaria de la reunión anual de la Virginia Philosophical Association en Randolph College en octubre del 2016, «Descartes, Meditation, and the Nature of Philosophy», y en Jorge Secada (2021). Aquí he omitido referencias a la bibliografía secundaria que el lector interesado puede encontrar en estos otros ensayos. 
Descartes parece ofrecerla al decirnos que buscaba asegurar la atención de sus lectores. Escribió en primera persona para que hiciesen suyos los pensamientos que ofrecía. De hecho, es bastante usual que los comentadores expliquen así este aspecto del libro.

Pero esto requiere algo de desarrollo. Una prueba matemática compleja requiere muchísima atención y cuidado sostenido pero no parece que se ganaría nada si se le formula en primera persona. Si buscamos ayuda en algún texto de Descartes, lo que encontramos es esto: «la metafísica... [está] en conflicto con muchos prejuicios sensoriales a los que nos hemos acostumbrado desde nuestros primeros años, y por consiguiente [la] conocerán solamente aquellos que verdaderamente se concentren y mediten y, en cuanto sea posible, retiren su mente de las cosas corporales» (AT, VII, 157). ${ }^{13}$ Los estudiosos cartesianos señalan que Descartes busca subvertir y reemplazar viejos hábitos cognitivos. Escribe en primera persona para acendrar epistémicamente al lector, quien adoptará él mismo esa persona y abandonará, con mucho esfuerzo, los prejuicios y hábitos que ha adquirido desde su nacimiento.

En efecto, las Meditaciones son un manual terapéutico, más allá de cualquier otra cosa que también puedan ser. Ofrecen un tratamiento para una dolencia cognitiva inherente a los seres humanos, originada de la unión de la mente con el cuerpo, que por lo tanto está sujeta a pasiones y sentimientos y debe confiar en la imaginación y las sensaciones para conocer el mundo en el que vive. Según Descartes, esta terapia epistémica es necesaria si queremos encontrar algo «firme y permanente en las ciencias» (AT, VII, 17). La unidad y coherencia de las Meditaciones resulta de ese proceso de cura epistémica y no es exclusivamente ni principalmente siquiera aquella de la pura argumentación racional.

13 Las referencias a la obra de Descartes son al volumen y páginas de la edición Adam Tannery (AT) (Descartes 1996) y están dadas en el cuerpo mismo del artículo. Los textos intercalados por el traductor se colocan entre corchetes, []. $\mathrm{Al}$ igual que en otras citas de este ensayo, cuando una referencia simplemente repite la anterior, se omite. Las traducciones son mías. 
En las obras de ficción solemos distinguir la voz del autor de las diversas voces dentro de la narración, sean tanto las de los personajes como la de un narrador impersonal. Estas distinciones son de suma importancia cuando se trata de interpretar este texto. No debemos tomar nunca al «yo» de las Meditaciones de Descartes como refiriéndose al autor o a su portavoz. Más plausible es que la identidad de ese «yo» sea el lector. Descartes confiaba en que a través de la lectura del texto, su estudio cuidadoso y su disposición a participar en los ejercicios reflexivos a los cuales los conduciría, sus lectores se convirtiesen realmente en meditadores (ver los textos citados arriba y AT, VII, 34 y 162-163). Las Meditaciones no describen esta empresa. Buscan, más bien, ser expresión de la radical transformación del meditador. Para Descartes, el lector y el yo meditativo vivirán por el mismo proceso de cambio, que cantarán ambos con una sola voz.

La Meditaciones suponen un diagnóstico y la terapia funcionará exclusivamente para quienes estén preparados a someterse a la disciplina que el libro exige (ver AT, VII, 9, 130 y 158). La dolencia que busca aplacar es la dependencia sensorial y el tratamiento meditativo le permitirá a la mente ejercitar su percepción puramente intelectual. El meditador no solamente adquirirá conocimiento certero sobre la naturaleza de las cosas, sino que estará listo para marchar a las fronteras de la ciencia y expandirlas firmemente.

Debemos matizar. Estrictamente, no es correcto hablar aquí de una enfermedad, puesto que depender de los sentidos no es un mal humano sino que constituye nuestra naturaleza misma y nos permite vivir nuestras vidas, y buscar y alcanzar fines propiamente humanos. No somos ángeles. Somos mentes encarnadas que deben obtener la salvación eterna viviendo bien, y para hacerlo requerimos la percepción sensorial y el comercio causal con la materia: «[t]oda la conducta de nuestra vida depende de los sentidos» (AT, VI, 81; ver VIII-1, 35-36). Las Meditaciones no conducen, pues, al abandono de los sentidos como un medio para adquirir conocimiento sobre el mundo y sobre nosotros mismos. Al contrario, cuando hayamos 
terminado el ejercicio meditativo, volveremos a confiar cotidianamente en los sentidos, al tiempo que investigamos la naturaleza por su intermedio.

Más aún, Descartes enfatiza que incluso durante el curso de las Meditaciones, correctamente asumidas, es extremadamente difícil, cuando no imposible, superar completamente la encarnación, la sentida presencia del cuerpo en nuestra consciencia y la natural tendencia a confiar en los sentidos y satisfacer los apetitos. Las Meditaciones concluyen con una advertencia. Habiendo afirmado que «en esta vida estamos condenados a equivocarnos», termina con estas últimas palabras: «debemos reconocer la debilidad de nuestra naturaleza» (AT, VII, 90). En los Principios de la Filosofía explica que dada la encarnación del alma y su arraigado hábito de tratar solo con objetos sensoriales, a «nuestra mente... [le resulta] muy difícil... atender a lo que no se presenta a los sentidos ni a la imaginación» (AT, VIII-1, 37).

El ejercicio meditativo centrado en Dios y el alma es arduo y agotador, pero es necesario para alcanzar algo «firme y duradero en las ciencias» y conseguir aquellos otros «beneficios» que inicialmente escapan a sus lectores y que, significativamente, menciona solamente en la edición latina de las Meditaciones (AT, VII, 17 y 159; y IX-1, 13. Ver IX-1, 123, nota a). La percepción sensorial induce al error cuando investigamos la naturaleza de las cosas; es un obstáculo si queremos conocernos como en verdad somos, las cosas en torno nuestro como son en sí mismas, y el orden y el fundamento último de la realidad toda (ver AT, VII, 157; ver también VIII-1, 3438). Desde una perspectiva cognitivamente idealizada, angelical, la dependencia sensorial es una dolencia. Entre sus síntomas están las constantes e interminables disputas entre los entendidos en prácticamente cualquier disciplina salvo las matemáticas.

Las Meditaciones conducen al lector a una condición inestable, medio desencarnada, de percepción puramente intelectual. Su unidad no es argumental ni siquiera cuando desplegamos sus razona- 
mientos según el orden de su descubrimiento. Se trata, en vez, de la unidad de una curación, el abandono de prejuicios enraizados, de hábitos epistémicos cultivados desde que nacemos y la liberación del poder de la acendrada intuición intelectual.

Escritas en primera persona, las Meditaciones despliegan toda la pasión que acompaña, como elemento integral, el proceso de conversión que va del hábito ignorante y cómodo a la contemplación disciplinada y dura pero provechosa. Este aspecto emotivo del texto tiende a pasarse por alto. $\mathrm{Y}$ hay quienes sostienen que se trata de mera retórica, diseñada para atraer al lector que medita y razona. Pero entonces persiste la pregunta: ¿por qué el estudio de argumentos y doctrinas tendría que involucrar tanta pasión?

Aun después de conceder que las Meditaciones son un manual para esta peculiar terapia cognitiva, sin embargo, podría insistirse que su fin último es la articulación de argumentos en apoyo de doctrinas discursivas. El proceso que lleva a establecer las verdades filosóficas resultaría ser considerablemente más complejo que el de un ensayo común y corriente, ya que supone cambiar radicalmente nuestras disposiciones epistémicas. Pero este reconocimiento no altera el hecho de que al final de cuentas el resultado son argumentos que llevan a conclusiones. En pocas palabras, la terapia meditativa conduce al lector a practicar mejor la investigación racional y a mejor comprender sus conclusiones discursivas; no es otra cosa que la propedéutica para la filosofía tal como usualmente se entiende.

Pero esto no encaja con el texto. En particular, y yendo al corazón mismo de nuestras dificultades interpretativas, tenemos este pasaje, el extraordinario aunque comúnmente ignorado rapto en el centro mismo de la obra:

Quiero detenerme aquí por un tiempo en la contemplación de Dios mismo, considerar detenidamente sus atributos, y observar la belleza de esta luz inmensa con asombro y adoración, en cuanto la mirada de mi intelecto oscurecido pueda soportarla. Pues así como creemos por la fe que la felicidad suprema en la 
próxima vida consiste en la mera contemplación de la majestad divina, así descubrimos por la experiencia que esta misma contemplación, aunque mucho menos perfecta, nos permite conocer la más grande alegría y satisfacción de la que somos capaces en esta vida (AT, VII: 52).

Este pasaje, recalquémoslo, no constituye una ruptura dentro de la obra, sea de estilo, sea de contenido. Y obliga a plantear interesantes cuestiones hermenéuticas, algunas de las cuales tendremos que abordar aquí. Repetidamente, el meditador menciona el tiempo dedicado a la contemplación y meditación fuera del curso explícito del texto, aunque en continuidad con él (ver, por ejemplo, AT, VII, 22-23, 34, 62 y 63). La cita es solamente un ejemplo notable, sorprendente por su intensidad mística.

Una pregunta es ¿cómo encaja este rapto con el resto del libro? ¿Y qué relevancia tiene para el tema que nos interesa aquí, la naturaleza de esta obra? ¿Se trata acaso de una digresión, tal vez un adorno retórico? ¿O es, como ha llegado a sugerir un comentarista, un intento de Descartes por aplacar los escrúpulos religiosos y teológicos de algunos de sus lectores para salvar de la censura sus propuestas científicas y filosóficas? ¿O se trata más bien de un momento integral e imprescindible del proceso meditativo?

Debemos mencionar ahora, aunque sea brevemente y sin mayor desarrollo, otro problema que enfrenta la adecuada interpretación de esta obra maestra de la literatura filosófica. Cuando las Meditaciones están por publicarse y, poco después, su autor insiste en que sus lectores le dediquen mucho tiempo y empeño, que se tomen al menos varios meses en el estudio de la primera y la segunda meditación. Pocos años más tarde, conforme ha ido conociendo la recepción que ha tenido el libro y ha ido concentrando sus esfuerzos en establecer su física en los colegios, le dice a sus lectores que las lean rápidamente y sin dedicarles mucho esfuerzo. Mientras que en las Meditaciones mismas el meditador habla con entusiasmo de las muchas cosas que quedan por explorar sobre Dios y el alma, en 
años posteriores Descartes advierte en contra de llevar el estudio de estos objetos metafísicos más allá de lo que él ya había hecho en ese libro.

¿Cómo entender esta radical contradicción respecto de su obra principal? ¿Pueden acaso reconciliarse estos textos? ¿Se dirigen a públicos distintos? ¿Cambió Descartes de opinión y, si lo hizo, sobre qué exactamente y cómo? Es un escándalo para los estudios cartesianos que no aborden frontalmente este asunto, esta inconsistencia textual, grave y reiterada, sobre su principal obra.

Preguntamos por la naturaleza de las Meditaciones. Podremos articular una interpretación de todo el libro, estemos o no de acuerdo con él, solamente cuando hayamos descubierto qué es este libro y cuál era la intención de su autor al escribirlo. Ninguna lectura que deje de lado alguna parte del texto, o que ignore algo de lo que su autor dice sobre él, que no considere todos los aspectos de esta extraña, única y magistral obra, podrá hacerle justicia y capturar lo que Descartes quiso enseñarnos al componerla. ${ }^{14}$

Como cualquier otro libro, este tiene muchos objetivos. Entre ellos están refutar el escepticismo; brindar un método para adquirir conocimiento; fundar sólidamente una ciencia estable y duradera y encarrilarla hacia su desarrollo fructífero; revelar la verdadera naturaleza de las cosas. Algunos se subrayan en el título en las que se demuestra la existencia de Dios y la inmortalidad del alma [la última frase posteriormente sustituida por la distinción entre el alma bumana y el

14 La tendencia a leer las Meditaciones como un tratado o ensayo, sea de epistemología o de metafísica o de fundamentación de la ciencia, está tan extendida que llamarla la interpretación estándar corre el riesgo de perder de vista que es prácticamente la única. Un ejemplo triste y lamentable de esta distorsión básica del pensamiento de Descartes es evidente en el uso que hace de él Raimon Pannikar: «hemos aceptado de forma acrítica la segunda regla de Descartes y hemos creído que la especialización nos aportaría "claridad y distinción”, confundiendo evidencia racional con comprensión» (2015a: 20). En lugar de «aceptado», esta frase debiera decir «tergiversado». Ver también Raimon Pannikar (2015b: 532). 
cuerpo] (AT, VII, xix y xx). Y hemos visto que lleva al lector a la apasionada contemplación de «Dios mismo».

Tal como indica su título, y como sugiere lo que hemos visto, esta obra es un manual para la meditación sobre los objetos de la filosofía primera, objetos que comparte, aunque no comparta también los métodos, y hasta puede ser que tampoco los fines, con la meditación religiosa tradicional. Sus múltiples propósitos no son independientes. Los comentaristas han estudiado las complejas relaciones entre sus objetivos epistemológicos, metafísicos y científicos. Hemos encontrado ahora otro, que sostendré es el más fundamental, la meditación encaminada hacia la contemplación de Dios y el alma. Sus otros objetivos, como mostraremos, no pueden desligarse de este, que los subyace y que unifica todo el texto.

Para apreciar cabalmente lo que vengo de afirmar, debemos responder ahora las siguientes dos preguntas: ¿qué es la meditación cartesiana? y ¿cómo se relaciona con las doctrinas y los argumentos discursivos?

\section{LA MEDITACIÓN CARTESIANA}

Descartes nunca abandonó las convicciones que le dan forma a las Meditaciones. Nunca dejó de confiar en la posibilidad de ascender hasta la contemplación y el amor de Dios por medios enteramente humanos y naturales. Esta contemplación está íntimamente ligada al autoconocimiento: la meditación sobre Dios está trenzada dialécticamente con la meditación sobre mi alma. Descartes tampoco abandonó nunca la noción de que esta meditación metafísica se relaciona dialécticamente con la investigación y argumentación discursiva, alimentándose de ella y a su vez guiándola.

Ahora bien, la meditación metafísica es valiosa en sí misma y rinde considerable beneficios para la vida de los seres humanos, pero es asequible para muy pocos. Y Descartes sí cambió de opinión 
sobre quiénes podrían llevarla a buen término. Su elitismo inicial se hizo más exclusivo aun, al punto en que dejó de creer que tuviese sentido hacerla pública y menos todavía en un libro impreso. Y llegó a pensar también que publicitar su metafísica contemplativa no le ayudaría a introducir su física en las escuelas, sino todo lo contrario, siendo su física la que mayores beneficios traería para la humanidad. La metafísica discursiva de los Principios bastaría para ese propósito y sería directamente el éxito explicativo de su física lo que ganaría la batalla contra la ciencia natural aristotélica.

Los lectores que estuviesen familiarizados con el género meditativo, como Descartes podía suponer estarían la mayoría de los suyos, sabrían que la meditación no es meramente instrumental, como no lo es la oración. Estas son Meditaciones de Filosofía Primera, es decir, filosóficas. Descartes enfrenta a los escolásticos y a los nuevos empiristas, como Hobbes o Gassendi, con una alternativa platónica radicalmente novedosa, el ascenso desde la caverna de la encarnación hasta la luz de «Dios, soberanamente bueno y fuente de toda verdad» (AT, VII, 22). Cuando posteriormente le aconseja a «las mentes débiles» no dedicar demasiado tiempo a la metafísica, está apuntando en dirección de una concepción de la metafísica que es distinta de, aunque está en continuidad con, aquella que se ocupa exclusivamente de los fundamentos discursivos de la física, tal como se presentan en el primer libro de los Principios o en el cuerpo del apéndice a las Segundas Respuestas (AT, VII, 7). ${ }^{15}$

Esta empresa metafísica es ciertamente más adecuada para un intelecto angelical, puro, que para el intelecto humano unido a un cuerpo. En ella, el argumento, la doctrina y el análisis conceptual están todos al servicio de una actividad sin fin, jamás acabada, la

15 En el texto citado, Descartes usa la frase para referirse a posibles lectores del Discurso del Método, escrito en francés mientras que las Meditaciones fueron escritas en latín, que no serían capaces de entender sus argumentos y llevar a buen término el ejercicio meditativo. No es inverosímil la extensión que propongo del uso de la frase. 
contemplación meditativa, ayudando a acceder a sus objetos y fijarlos. En este contexto, el progreso filosófico, en cuanto tenga cabida aquí, no se mide en términos del éxito para responder preguntas sino por la actividad misma de meditación y comprensión, por su progresivo pero interminable enriquecimiento. Esta es una actividad que vale toda una vida, hasta toda la historia humana.

Entender, según Descartes, es percibir clara y distintamente un objeto no sensorial y puramente intelectual (AT, VIII-1, 17; ver también, por ejemplo, VII, 34). Por tanto, la meditación cartesiana es la percepción contemplativa del intelecto puro, dirigida a los objetos de la filosofía primera. ${ }^{16}$ Pero la meditación no es el entendimiento proposicional y difiere de un acto discreto de comprensión, la comprensión clara y distinta de, por ejemplo, las frases «un triángulo tiene tres lados» $\mathrm{O}$ «la causa debe dar cuenta de la totalidad de su efecto». La contemplación meditativa es peculiarmente dinámica y abierta; no es estática ni tampoco enteramente pasiva y no se completa jamás.

Conforme el intelecto puro se libera del cuerpo, se percibe a sí mismo y al mundo de objetos puramente intelectuales que contiene, los que se le revelan gradualmente. Así, el meditador adquirirá «el necesarísimo... conocimiento de Dios y de nuestra alma» como mejor se puede poseer en esta vida (AT, III, 695). Estos objetos de meditación son infinitos cada uno a su manera y por consiguiente inagotables. La meditación no da solamente información sobre ellos, sino que lleva a una comprensión creciente de su naturaleza, mostrando cómo percibirlos mejor, cómo develar más de ellos, sin buscar llegar nunca a una percepción final y completa. Como dice el meditador hacia el comienzo del último tercio de la obra, «queda

16 Conviene subrayar que, como queda claro, para Descartes meditar es tanto considerar detenidamente para llegar a la contemplación, como la contemplación misma, que se va ejercitando de forma progresivamente más completa y rica. Por así decirlo, meditar es ir descubriendo e interactuando con los objetos de contemplación, Dios y el alma. 
mucho por investigar sobre... Dios, mucho sobre... mí mismo..., tal vez... para otra ocasión» (AT, VII, 63).

La meditación es una forma de percepción pasiva, pero el meditador no permanece pasivo en ella. Descartes afirma que «el entendimiento es la pasividad de la mente y la voluntad su actividad» pero «apenas y rara vez entendemos algo sin al mismo tiempo querer algo» (AT, III, 372; ver también XI, 342). Estos objetos, Dios y mi alma, no pueden percibirse sin comprometer la voluntad, que buscará activamente permanecer en su contemplación. Conforme el meditador se percibe a sí mismo, y reconoce su verdadero valor, se ve poseído por la pasión de la autoestima (ver AT, XI, 443-445).

El amor «impulsa al alma a buscar unirse gustosa y voluntariamente a los objetos» que considera buenos para ella (AT, XI, 387). No puede entonces haber amor más grande que el amor de Dios, puesto que «Dios es el bien supremo... incomparablemente más perfecto que criatura alguna» (AT, V, 82; ver XI, 374). Este reconocimiento llevará al meditador «a unirse gustoso» a Dios, buscando hacerse uno con Él, una parte de un todo cuya otra parte es Dios (AT, XI, 387; ver también y comparar V, 56). Pero deberá luchar y esforzarse para no perder su asidero, para que las sensaciones y las inclinaciones naturales de su mente encarnada no minen su percepción de este objeto infinito y puramente intelectual.

Tanto los esfuerzos requeridos para acceder al objeto y luego persistir en él, como el amor que esta contemplación origina en su alma, ocupan su voluntad. Como hemos visto, la contemplación de Dios, aunque una función del intelecto, lleva al meditador a un estado de «máxima satisfacción», capturado por la «belleza de [la] inmensa luz» de su objeto (AT, VII, 52). Es un estado comparable, aunque «mucho menos perfecto» que el de la visión beatífica. La meditación cartesiana es una suerte de misticismo intelectual.

En las Meditaciones hay dos voces. Una es la voz explícita, en primera persona, del meditador, que el lector atento y exitoso hará suya. La otra es la voz del autor, detrás del texto, guiando al lector 
meditativo a través del proceso de dejar de lado sus sentidos y su imaginación, y con ellos los objetos corporales, protegido en cuanto sea posible de la inevitable presencia de su cuerpo. «No puedo abrir los ojos de mis lectores», explica Descartes, «ni obligarlos a prestar atención a las cosas que deben examinarse para asegurar el conocimiento de la verdad; lo único que puedo hacer es, por así decirlo, señalar con el dedo» (AT, III, 283).

Al leer hoy en día las Meditaciones debemos escuchar ambas voces, el meditador y su creador, y estudiarlas ambas. Conforme se desarrolla el texto, Descartes anticipa los temas y objetos meditativos -el alma, Dios, la libertad, la verdad y el bien, el pecado y el error, y el significado de la vida- objetos y temas que se irán develando progresivamente. Primero percibido tenuemente, el meditador se irá familiarizando con él, lo irá comprendiendo mejor y le permitirá irse revelando mejor ante su alma. El proceso es parecido a la reminiscencia. Un hecho olvidado y enterrado en la mente se recuerda poco a poco. Una primera pista, un signo, da inicio a este proceso que nunca llega a completarse perfectamente.

En varios niveles, las Meditaciones son un texto dialéctico. Como quien mira y remira viendo cada vez más, así el meditador una y otra vez vuelve sobre el camino ya andado, construyendo sobre los resultados obtenidos para ver y comprender mejor su alma y Dios (ver AT, VII, 24, 25, 29-30, 36, 63). La meditación misma es un proceso dialéctico en el que el objeto transforma al sujeto que puede así percibirlo y amarlo mejor y ser nuevamente transformado por él. Más aun, la meditación sobre mí mismo y la meditación sobre Dios van de la mano, alimentándose mutuamente. El ascenso de la mente a Dios se inicia con el autoexamen y el autoconocimiento y llega a Dios desde la idea de Él en su alma.

Dios se introduce primero en el contexto del examen cognitivo radical de la Primera Meditación (ver AT, VII, 21). La reflexión sobre la cera descubre un mundo interminablemente rico dentro del 
alma, sirviendo así de preludio para el descubrimiento del Dios perfectísimo en la Tercera Meditación (AT, VII, 33). La contemplación de «Dios mismo» al final de esa meditación introduce la percepción de mi libertad y mi voluntad infinita en la Cuarta, aspectos de mi alma que no solamente dan testimonio de mi creador sino que literalmente comparto con Él (ver AT, VII, 56-58). El paso de la idea de Dios a Dios mismo al final de la Tercera Meditación anticipa una visión que propiamente se dará solo en la Quinta.

Como sucede a través de la obra, la meditación sobre el alma y sobre Dios están entrelazadas y suponen actos de percepción intelectiva que nutren y sirven de apoyo al discurso argumental, tanto como este los introduce y origina: el autoconocimiento y el reconocimiento de la real dimensión de mi voluntad libre, así como el conocimiento certero de la existencia de Dios, resultado de la meditación cartesiana, son ellos a su vez necesarios para las múltiples otras finalidades que tiene esta obra y que hemos mencionado anteriormente. ${ }^{17}$

Felizmente el desarrollo de las ciencias naturales, una vez que hayan sido colocadas sobre cimientos sólidos, no requiere emprender nuevamente esta actividad meditativa. Las conclusiones metafísicas discursivas, una vez establecidas, pueden emplearse sin necesidad de volver a pasar por el difícil ejercicio de descubrirlas. En un texto muy temprano, escrito probablemente entre 1619 y 1622, el joven Descartes había especulado que «[a]quellos que por falta de inteligencia..., no puedan hacer descubrimientos empleando primeros principios, podrán reconocer el valor real de las ciencias y esto les permitirá llegar a un juicio acertado respecto del valor de las cosas» (AT, X, 215).

Desde el punto de vista del proyecto propiamente meditativo, la recepción de las Meditaciones fue desastrosa. Ni siquiera sus

17 Demostrar esta afirmación excede por mucho nuestros fines aquí. 
mejores lectores, ni aun el gran Arnauld, ${ }^{18}$ comprendieron plenamente el libro. Esta decepción se vio reforzada por el fracaso de la correspondencia inicial con la princesa Isabel de Bohemia (16181680), que lo llevó a escribir eventualmente Las Pasiones del Alma, un tratado para manipular la mente encarnada obviando la práctica meditativa como medio para controlar las pasiones. Esto, aunado al hecho de que lejos de servir para establecer su ciencia natural o ser necesarias para su desarrollo resultaron más bien ser un obstáculo dada la falta de inteligencia de sus lectores, explican plena y coherentemente su cambio de opinión respecto de la atención y esfuerzo que debía invertirse en ellas.

En 1647, hacia el final de su vida, Descartes abordó dos preguntas que su amigo Pierre Chanut (1601-1662) le había presentado de parte de la reina Cristina de Suecia (1626-1689): «si la luz natural por sí sola enseña el amor de Dios y si uno puede amarlo por el solo poder de esa luz» (AT, IV, 607). Descartes respondió que él no tenía «duda alguna de que verdaderamente podemos amar a Dios por el solo poder de nuestra naturaleza... pero solo si meditamos con mucha atención, ya que continuamente nos distrae la presencia de otros objetos» (AT, IV, 607-608). Y luego articuló «la manera de llegar» a este amor, manera que notable y claramente reformula la ruta seguida por el meditador en las Meditaciones. En su respuesta, Descartes enfatiza que «el alma debe estar muy retirada del tráfico de los sentidos si va a representar para sí las verdades que despiertan ese amon». Finalmente, explica que la mera «idea de semejante unión [con Dios] basta por sí sola para... causar una pasión violenta» (AT, IV, 610; ver XI, 390).

18 Antoine Arnauld (1612-1694), autor de las Cuartas Objeciones a las Meditaciones que Descartes, en privado, dice considerar «las mejores de todas..., porque él, más que cualquier otro, ha tocado el sentido de lo que digo, que yo ya había previsto pocas personas entenderían, ya que hay pocos que quieran o puedan detenerse a meditar» (AT, III, 330). 
Las Meditaciones constituyen el itinerario para que el alma pueda elevarse hasta el amor de Dios, itinerario que Descartes volvería a esbozar explícitamente para Chanut y Cristina de Suecia muchos años después (ver AT, VII, 47-58).

\section{Descartes y La TRADición MEDITATIVa}

Los múltiples fines de las Meditaciones sitúan a esta obra en diversas tradiciones. Los estudiosos han examinado su lugar en la historia del escepticismo antiguo y renacentista y de la emergente ciencia moderna y sus precursores atomistas. Recientemente, sus profundas relaciones y deudas con las diversas corrientes aristotélicas de la filosofía escolástica, esbozadas primero por Etienne Gilson y otros en la primera parte del siglo pasado, han sido estudiadas y discutidas en detalle, como también se han explorado sus temas y doctrinas agustinianas, ya señaladas por Arnauld cuando primero se publicaron (ver AT, VII, 197-198, 205 y 216-217; ver también I, 376 y II, 435; III, 247-248 y 261; y IV, 113). Hasta sus relaciones con el Anfitrión de Plauto han sido puestas al descubierto por un estudioso en extremo entusiasta que exageradamente describe esta comedia romana como «la fuente genuina...[,] la fuente original, la auténtica fuente del sistema cartesiano» (García-Hernández 1997: 15-16). ${ }^{19}$

Sorprende, entonces, la poca atención que se le ha dedicado a su carácter propiamente meditativo y, por consiguiente, a su inserción en la correspondiente tradición de espiritualidad cristiana. Aunque algunos comentaristas han indicado el evidente aspecto meditativo del libro, particularmente en cuanto a su estructura y forma literaria, no se han explorado realmente sus implicaciones filosóficas. La atención que le dedican los filósofos al argumento y la doctrina discursivos, les dificulta atender o incluso percibir siquie-

19 Ver al respecto Descartes (AT, III, 752, nota c). 
ra la dimensión meditativa de las Meditaciones, menos aun entender su significado pleno o integrarlo a sus fines filosóficos. Se trata de una laguna considerable en nuestra comprensión de esta obra y, en general, de la metafísica cartesiana. Las relaciones entre Descartes y esta tradición son críticas si buscamos interpretarlo correctamente.

Adrien Baillet, el biógrafo de Descartes, llamó a la carta a Chanut de febrero de 1647, que hemos citado anteriormente, una «Disertación sobre el amor». ${ }^{20} \mathrm{Al}$ responder afirmativamente las preguntas de Chanut, Descartes alude a quienes, por el contrario, mantienen que sin el cristianismo no es posible amar a Dios verdaderamente. Como hemos visto, él insiste: «podemos amar a Dios por el mero poder de nuestra naturaleza... [M]e atrevo a decir que es la pasión más placentera y más útil que podemos tener en esta vida, y que hasta puede ser la más fuerte» (AT, VII, 607-608).

Descartes aclara que hay «dos razones considerables» para negar lo que sostiene:

La primera es que los atributos de Dios que consideramos comúnmente están elevados tan por sobre nosotros que de ninguna forma podemos concebir que nos convengan, lo que explica que no busquemos unirnos a ellos gustosa y voluntariamente. La segunda es que como no hay nada de Dios que la imaginación pueda captar, aunque pudiésemos tenerle un amor intelectual, parece que no podemos tenerle un amor sensual, puesto que tendría que pasar por la imaginación para alcanzar los sentidos desde el intelecto. Por eso no me sorprende que algunos filósofos estén convencidos de que lo único que nos hace capaces de amar a Dios es la religión cristiana, que enseña el misterio de la encarnación según el cual Dios se rebajó hasta el punto de hacerse como nosotros; y que quienes sin conocer este misterio han aparentado tener una pasión por alguna divinidad no han amado al Dios verdadero en absoluto (AT, IV, 607).

20 Ver Descartes (2013: 12, nota 14 y 18). 
Notemos que Descartes no le atribuye las dos razones que menciona a nadie. ${ }^{21}$ Más bien, las ofrece como explicación de por qué no le sorprende que «algunos filósofos» («quelques Philosophes») crean que solo se puede llegar al amor de Dios por medio de Cristo. Enfrenta a sus críticos pero busca permanecer en el ámbito puramente filosófico y evita entrar en discusiones teológicas. Notemos también que estas dos razones se aplican, justamente, al peculiar camino cartesiano que llega al amor de Dios desde el puro intelecto.

Tiene sentido preguntar ¿a quién enfrenta aquí Descartes? ¿Quiénes son aquellos contra los que está proponiendo una manera de alcanzar el amor de Dios sin recurso a la gracia divina, una manera que, como hemos visto, se encuentra en la médula de las Meditaciones? ¿Cuál es, en otros términos, el contexto en el que debemos colocar este libro cuando lo vemos como un manual para la meditación sobre Dios y el alma?

La respuesta primera y obvia, aunque imprecisa y genérica, es que se refiere a la tradición de espiritualidad cristiana, dejando de lado aquí la relación con la escolástica sobre este punto. Por cierto, una obra en la que encontramos aseveraciones explícitas que Descartes parece estar negando es el Itinerario de la mente a Dios de san Buenaventura. En el prólogo nos dice el santo que la única manera de alcanzar «aquella paz que sobrepasa a todo entendimiento» es por medio del «ardentísimo amor al Crucificado» (2010: I, 474 y 475). ${ }^{22} \mathrm{Y}$ nos explica que en

Dios..., nadie entra rectamente sino por el Crucificado. Y en verdad, quien no entra por la puerta, sino sube por otra parte, ése es

21 No es difícil, sin embargo, encontrar posibles referencias en la literatura espiritual que examinaremos a continuación, contemporánea con Descartes. Como mero ejemplo, ver santa Teresa de Jesús: «no alcanza la imaginación -por más sutil que sea- a pintar ni trazar cómo será la luz, ni ninguna cosa de las que el Señor me [daba] a entender» (2012: 207).

22 Ocasionalmente he introducido ligeros cambios en la traducción. La cita bíblica, en cursiva, viene de Filipenses 4, 7. 
ladrón y salteador.....No puede entrar uno por la contemplación en la Jerusalén celestial si no es entrando por la sangre del Cordero como por la puerta. Nadie, en efecto, está dispuesto en manera alguna para las contemplaciones divinas que llevan a los excesos mentales, si no es... varón de deseos. Y los deseos se inflaman en nosotros de dos modos: por el amor de la oración... y por un destello de comprensión (fulgorem speculationis), por el que la mente directísima e intensísimamente se vuelve (se convertit) hacia los rayos de la luz (San Buenaventura 2010: I, 476). ${ }^{23}$

El supuesto es que ese «fulgor de especulación» es un don gratuito de Dios, que se hace presente al alma. Justamente, san Buenaventura nos dice que le escribe a los que están ya predispuestos por «la gracia divina, a los humildes y piadosos, a los arrepentidos y devotos, a los... amantes de la sabiduría divina, de ella enardecidamente deseosos» (2010, I: 477). Y advierte contra los que por esta misma especulación luminosa inoportunamente emprendida o mal llevada terminan cayendo «en un foso más profundo de tinieblas».

Todo esto, sin embargo, es típico de los escritores cristianos al tratar estos temas. Si buscamos determinar el contexto histórico de las Meditaciones, debemos precisar un tanto nuestro enfoque.

Por razones fácilmente comprensibles, quienes resaltan los aspectos meditativos formales de las Meditaciones suelen concentrarse en la posible influencia de los Ejercicios Espirituales de San Ignacio de Loyola. En efecto, el pensamiento de Descartes le debe mucho al escolasticismo tardío que los jesuitas le enseñaron en la escuela de La Flèche. E influyeron sobre su concepción de la naturaleza de la filosofía en cuanto consideró que las preguntas filosóficas admiten y exigen una resolución definitiva, doctrinal y discursiva. Pero también adoptó explícitamente una concepción radicalmente distinta de la disciplina, de su práctica y del género literario adecuado para escribirla, y articuló una alternativa platónica cristiana en oposición al aristotelismo escolástico de los jesuitas, buscando recuperar un

23 Las citas bíblicas vienen de San Juan 10, 1 y Daniel 9, 23. 
lugar para la intuición intelectual metafísica no discursiva, sin solución de continuidad con el entendimiento proposicional, la doctrina filosófica y las ciencias naturales.

Desde la perspectiva del cristianismo cartesiano, el ascenso a la contemplación del bien está tanto fuera de este mundo como que es útil para vivir en él, tanto asequible a poquísimos como beneficioso para toda la humanidad. Y, en significativa oposición a mucha sabiduría aristotélica, es imprescindible y esencial para la investigación metafísica discursiva.

La espiritualidad francesa de comienzos del siglo XVII alberga una reacción contra la inflexibilidad jesuita. ${ }^{24}$ Evelyn Underhill ha identificado dos corrientes en la espiritualidad mística cristiana de ese tiempo. Una de ellas «se origina dentro de la Iglesia Católica y está en contacto con la gran tradición mística cristiana. Llega a tener su mayor desarrollo en Francia y tiende a enfatizar los aspectos personales e íntimos de la contemplación» (2006: 524). ${ }^{25}$ Es aquí, entonces, que debemos indagar si queremos situar a la meditación cartesiana en el contexto de otras perspectivas sobre el camino que lleva al alma a la contemplación amorosa de Dios, perspectivas con las que Descartes estaría interactuando, tanto temática como intencionalmente. Las raíces inmediatas de este movimiento de renovación espiritual francés se encuentran en los carmelitas descalzos españoles del siglo anterior.

Las principales figuras de la reforma carmelita del siglo XVI son santa Teresa y san Juan de la Cruz. Con sus obras escritas ambos buscan ayudar a las almas a alcanzar y desplegar, en esta vida, el amor de Dios. Sabemos de la influencia de la primera sobre santa Rosa a través de su examinador y protector el doctor Juan del Cas-

24 Ver los artículos «Bérulle, Pierre de», «Francia» y «Mística (notas históricas)» en Luigi Borriello et al. (2002: 317-320, 736-743 y 1182-1195) y William M. Thompson (1989).

25 La traducción del inglés es propia. 
tillo. ${ }^{26}$ De la santa limeña, empero, no queda nada escrito más allá de unas cuantas hojas. Podemos especular, además, que lo que haya escrito y se haya perdido no tendría mayor valor por su originalidad o por el pensamiento que pudiese expresar, sino como testimonio de una vida de excepcional santidad. En efecto, santa Rosa es un ejemplo emblemático del amor de Dios, el amor del alma que busca gozosa unirse a Dios, su bien supremo, amor que ocupa los escritos de los dos santos carmelitas y que san Juan describe en versos difíciles de superar:

¡Oh noche que guiaste!;

¡oh noche amable más que la alborada!;

¡oh noche que juntaste

Amado con amada,

amada en el Amado trasformada! (San Juan de la Cruz 2009: 254).

San Juan distingue dos maneras en que el entendimiento puede recibir y aprehender sus objetos: «una es natural y la otra sobrenatural. La natural es todo aquello que el entendimiento puede entender, ahora por vía de los sentidos corporales, ahora por sí mismo. La sobrenatural es todo aquello que se da al entendimiento sobre su capacidad y habilidad natural» (2009: 317). Para llegar a Dios, la manera natural es, primero, «noche..., de la parte sensitiva», cuando el alma emprende «la privación y purgación de todos sus apetitos sensuales acerca de las cosas exteriores del mundo y de las que eran deleitables a su carne, y también de los gustos de su voluntad» (2009: 258-259). Los sentidos, aunque adecuados para conocer los cuerpos, son un obstáculo en el camino hacia Dios.

Pero el entendimiento mismo es noche en esta ruta, porque el «medio..., por el que ha de ir el alma a [la] unión [con Dios], lo cual es la fe, es también oscura para el entendimiento» (2009:

26 Establecida por Mujica (2005: 140-208) y aceptada por Del Busto Duthurburu (2006). 
260). ${ }^{27}$ (Comparar con AT, VII, 147-149). Y lo es tanto en cuanto el entendimiento se ocupe de cosas materiales como de cosas espirituales, como es el alma. Hay, sin embargo, una manera de llegar a vislumbrarlas: «aunque estas visiones de sustancias espirituales no se pueden desnudar y claramente ver en esta vida con el entendimiento, se pueden, empero, sentir en la sustancia del alma con suavísimos toques y juntas, lo cual pertenece a los sentimientos espirituales» (2009: 377). Es por medio de la voluntad y el deseo, más que del entendimiento propiamente, que se puede tocar y de esa forma percibir en algo el espíritu.

En Las Moradas del Castillo Interior de santa Teresa encontramos pensamientos semejantes. El alma debe entrar «dentro de sí» para ir ascendiendo hasta el lugar más íntimo donde habita Dios en ella, y al cual no se llega desde el entendimiento ni la razón. La puerta es, más bien, la oración: «son las almas que no tienen oración como un cuerpo..., que aunque tiene pies y manos, no los puede mandar tullido. Que así son, que hay almas tan enfermas y [dadas] a estarse en cosas exteriores, que no... pueden entrar dentro de sí» (2012: 474). ${ }^{28}$

Pero no solamente las cosas corporales impiden el ascenso del alma hasta el encuentro con Dios en ella, «pues dentro de esta alma hay morada para Dios» (2012: 568). El pensamiento y la imaginación pueden ser un obstáculo si no se le sobrepasa: «para aprovechar mucho en este camino y subir a las moradas que deseamos, no está la cosa en pensar mucho, sino en amar mucho» (2012: 497). ${ }^{29}$ Como san Juan, santa Teresa matiza en el llamado Libro de las fundaciones la eficacia de la meditación imaginativa: «algunos he topado que les

\footnotetext{
27 Ver también allí mismo 312-346 y 374-401.

28 En algunas citas he modernizado ligeramente el texto para facilitar su lectura, por ejemplo, poniendo «así» en el lugar de «ansí» o «exterion» en vez de «esterion».

29 Santa Teresa habla aquí de «pensamiento» en un sentido cercano a «imaginación» como queda claro en la siguiente sección cuando escribe «pensamiento, o imaginativa por que mejor se entienda» y la distingue del «entendimiento» que «es una de las potencias del alma».
} 
parece está todo en el negocio del pensamiento... No digo que no es merced del Señor, quien siempre puede estar meditando en sus obras, y es bien que se procure; más... no todas las imaginaciones son hábiles de su natural para esto, mas todas las almas lo son para amar... [E]l aprovechamiento del alma no está en pensar mucho, sino en amar mucho» (2012: 688). En el Libro de la Vida, también advierte a «los que discurren mucho con el entendimiento... que no se les vaya todo el tiempo en esto... sino que se representen delante de Cristo y, sin cansancio del entendimiento, se estén hablando y regalando con Él, sin cansarse en componer razones» (2012: 80-81).

En 1604, el cardenal Pierre de Bérulle (1575-1629), una de las figuras centrales de la renovación espiritual francesa, estableció el primer convento de monjas carmelitas descalzas en Francia (Evelyn Underhill 2006: 526). Posteriormente, en 1611, fundaría la Congregación del Oratorio, que tuvo una buena disposición hacia la filosofía cartesiana. Sabemos que Bérulle estuvo presente en una reunión en 1628 en casa del nuncio papal en París, el cardenal Giovanni Francesco Guido di Bagno (1578-1641), a la cual también asistió Descartes. ${ }^{30} \mathrm{Y}$ sabemos que durante la reunión, Descartes esbozó su pensamiento metafísico e impresionó a Bérulle, que lo alentó a publicar sus ideas y lo citó para conversar sobre ellas. Sabemos, finalmente, que después de reunirse con Bérulle, Descartes dejó París para recluirse y avocarse al desarrollo de su pensamiento metafísico, proceso que culminó en 1641 con la publicación de las Meditaciones. Bérulle murió al año siguiente de reunirse con Descartes. No tenemos suficiente información sobre su relación con nuestro filósofo como para saber cuánto conoció de su pensamiento ni cómo hubiese reaccionado frente a su gran obra, aunque no sea inoportuno especular que tal vez habría sido un lector más perceptivo de su dimensión meditativa y contemplativa que los que encontramos en

30 Sobre la reunión de 1628 en casa de Guido di Bagno, ver Jorge Secada (2000: 39-40). 
las objeciones que las acompañan o en la correspondencia cartesiana. Después de todo, el camino platónico y sus imágenes le parecía adecuado al cardenal para hablar del ascenso a Dios por medio de la fe: «cuando primero contemplamos y pensamos la excelencia, lo extraordinario y único de nuestro Señor Jesucristo y del sagrado misterio de la Encarnación..., somos como alguien que al salir de una caverna profunda y oscura se encuentra en una alta cima y contempla por primera vez el sol» (1989: 114).

Otra figura importante para nuestros propósitos tanto por su amistad con Bérulle y su lugar fundamental en la reforma católica francesa de estos años, como por el reconocimiento que obtuvo su Tratado del amor de Dios durante los años en que Descartes desarrollaba su metafísica meditativa, es san Francisco de Sales, a quien hemos mencionado hacia el inicio de este ensayo. Según san Francisco, «entre todos los amores, tiene cetro de excelencia el amor divino» (2010-2016: II, 118). En esto Descartes concuerda con él (ver AT, IV, 612-613). Pero, en oposición a Descartes y siguiendo a san Juan y santa Teresa, san Francisco agrega que «el amor sagrado es como un hijo del milagro, pues la voluntad humana no lo puede concebir si el Espíritu Santo no lo infunde en nuestros pechos; y como ser sobrenatural, debe presidir y reinar sobre todos los afectos, sobre el entendimiento y la voluntad» (San Francisco de Sales 2010-2016: II, 119). En el capítulo XVII del primer libro del Tratado del amor de Dios, san Francisco sostiene explícitamente que «[C]on solo las fuerzas naturales no es posible amar a Dios sobre todasl as cosas» (2010-2016, II: 149).

Su principal objeción, sin embargo, no es por la incapacidad del intelecto humano sino por la debilidad de su voluntad: «nuestros espíritus..., animados por una santa inclinación natural hacia Dios, poseen mayor luz en el entendimiento, para comprender su amabilidad, que fuerza en la voluntad para amarla, pues el pecado debilita mucho más la voluntad humana que el entendimiento». Concede que «la rebeldía del apetito sensitivo, que llamamos concupiscencia, 
turba en realidad el entendimiento» pero insiste que más mina la voluntad que «no puede progresar mucho en el amor divino, siguiendo los impulsos y consejos de la razón y del impulso natural». Y subraya que a pesar de toda inclinación natural, «amarlo sobre todas las cosas, que es la verdadera madurez del amor debido a la suprema bondad, solo es propio de los corazones animados y asistidos por la gracia celestial» (2010-2016, II: 151). Por otro lado, «el pequeño amor imperfecto, cuyo impulso siente la misma naturaleza, no es más que un querer sin querer, un querer que querría pero que no quiere; querer estéril que no produce verdaderos efectos; querer del paralítico, que ve la piscina saludable del amor santo y no tiene fuerzas para arrojarse a ella». ${ }^{31}$ En armonía con el pensamiento católico ortodoxo, sin embargo, san Francisco concede que «aunque por la sola inclinación natural no podemos llegar a la dicha de amar a Dios como conviene, si fielmente la secundamos, la dulzura de la piedad divina nos ayudará a ir más adelante» (2010-2016, II: 152).

San Francisco también subraya que el control del apetito y la disciplina de la voluntad requeridos para llegar, con la ayuda de la gracia divina, al amor de Dios no son incompatibles con el cumplimiento de «los verdaderos y legítimos deberes de nuestra condición» (2010-2016, II: 644). Para amar a Dios debemos encausar todo otro deseo, porque «[q]uien desee alguna cosa sin desearla por Dios, desea por ello menos a Dios» (2010-2016, II: 643). Aunque «[1]as almas que desean de todo corazón amar a Dios, cierran el entendimiento a las cosas mundanas», igual podemos vivir responsablemente y amándolo, cumpliendo con nuestros deberes hacia nosotros mismos y hacia toda criatura: «amar al prójimo por caridad es amar a Dios en el hombre o al hombre en Dios; es querer a Dios solo por su amor y a la criatura por su amor también» (20102016, II: 542).

Esta tradición de espiritualidad católica, contemporánea con Descartes, es el contexto en el que debemos situar las Meditaciones, que comparten con ella la búsqueda de la contemplación y el amor

31 El texto contiene una alusión a San Juan, 5, 7. 
de Dios, pero de la que difieren radicalmente no solo, como veremos, por su motivación, sino al mantener que podemos alcanzar este fin sin la ayuda de la gracia y, aparentemente, por medio del puro entendimiento. Vemos ahora la pertinencia de la referencia a santa Rosa de Lima. Ella representa de manera viva y pura la vía de san Buenaventura, san Juan, santa Teresa y san Francisco. El meditador cartesiano y la santa limeña se sitúan en lados opuestos del mismo espacio; están enfrentados en un mismo campo de juego.

\section{MEditación, AMOR y LA NATURALEZa de LA FILOSOFÍA}

Empecemos con una diferencia importante entre la motivación cartesiana originaria del ejercicio meditativo y la que encontramos en la tradición cristiana. Hemos visto que san Francisco habla de una tendencia natural hacia el amor de Dios. Esta disposición no es ni mera ni estrictamente cognitiva. Es una inclinación vital hacia la trascendencia y que por consiguiente compromete la totalidad de la persona y su existencia. La vida de santa Rosa ejemplifica claramente este punto.

La motivación cartesiana, por otro lado, es primeramente filosófica y cognitiva. Por eso, como hemos visto, lo que explícitamente motiva al meditador al inicio de las Meditaciones es la búsqueda de algo firme y duradero en las ciencias, y por ello también, cuando se haya asegurado ese fin, Descartes puede proponer, llevado por la mala recepción de este aspecto de su obra, dispensar de ella por más que siguiese pensando que su práctica conlleva otros beneficios considerables. Es cierto que sin el éxito de la meditación, la filosofía queda no solo incompleta sino sujeta a la duda metafísica (ver AT, VII, 36). Pero esto no invalida ni la ciencia ni el discurso filosófico resultantes.

Ligada a esta diferencia encontramos otra igualmente significativa. El Dios de santa Rosa de Lima no es un Dios de atributos, un Dios sobre el cual la mente discurra, aun contemplándolo. Es 
más bien un Dios personal. La santa ve a Dios a través de Jesús, pero no con los sentidos, «sino con el ánima, con muy grande certidumbre, sin duda ninguna» pero «siempre estaba como una niebla delante, entre el Niño Jesús y ella; y desde el Niño Jesús a su ánima y al cuerpo le venía una cosa de muy grande deleite... [como] una llamarada de fuego y que no era fuego sino una cosa que ella no sabía significar». ${ }^{32}$ Explícitamente recalca que «no entendía ella esos lenguajes de hablas intelectuales» sino que «de la boca de Jesucristo salía una cosa muy linda y entraba por su boca de ella, que no sabe qué se era, mas que por allí se entendían Cristo y ella». Aunque podía hablar de la Trinidad y la Encarnación de forma sorprendente dado que era una «mujer sin letra alguna», cuando describe a Dios lo hace metafórica o poéticamente como «mar infinito o nube infinita» (Del Busto Duthurburu 2006: 163). ${ }^{33}$

Santa Rosa conoce a Dios dentro de su alma «como una luz, que no tenía, ni forma, ni medida, ni fin, sino era incomprensible... [M]ás la percibía el alma, por unos admirables efectos de vitales efluxiones que por su substancia. Y... estos efectos eran afectos tiernos de amor, un firme y dulce gozo sobre todos los gozos imaginables». ${ }^{34}$

Aunque la visión del meditador cartesiano excede cualquier discurso y tiene lugar propiamente fuera del texto mismo, no puede desligarse, tanto por la manera en que a ella accede como por lo que de ella concluye, de la aprehensión de Dios como sumamente perfecto, es decir, «eterno, infinito, inmutable, omnisciente, omni-

32 Juan del Castillo en testimonio citado en José Antonio del Busto Duthurburu (2006: 183), ver también Del Busto (2006: 243-244). Sobre la vida espiritual de Santa Rosa y sus dimensiones teológicas y místicas, ver Ramón Mujica (2005: 135-208), a quien del Busto sigue. Este capítulo contiene un análisis detallado de las hojas autógrafas de Santa Rosa, las cuales han sido reproducidas, transcritas, extensamente analizadas y comentadas en Carrasco Ligarda (2016: 17-63).

33 Ver también Del Busto Duthurburu (2006: 182) y Mujica (2005: 174-183).

34 Fray Juan Meléndez citado en Mujica (2005: 180-181). 
potente y creador de todas las cosas» o como «una sustancia infinita, eterna, inmutable, independiente, supremamente inteligente, supremamente poderosa y que me ha creado a mí y a todo lo demás» (AT, VII, 40 y 45; y IX-1, 32 y 35-36). ${ }^{35}$ El Dios del meditador es, por así decirlo, el Dios de los filósofos, aunque sea también, y en especial conforme va avanzando en su contemplación y considerando su providencia y su bondad personal y desarrollando su vínculo amoroso con Él, el Dios de amor de la religión cristiana.

Tenemos, entonces, un contraste en la motivación para emprender la meditación sobre Dios, contraste que va de la mano de un contraste al menos inicial en el objeto mismo de contemplación. Como veremos, resulta de suma importancia para Descartes que este contraste se mantenga y no acabe, terminado con éxito el ejercicio, colapsado.

Estos contrastes se relacionan con otros, también evidentes al comparar el texto de las Meditaciones con los de san Juan, santa Teresa o san Francisco. La meditación cartesiana es episódica. El meditador debe emprenderla «una vez en la vida» aunque sabemos que Descartes mismo la ejercitó con más regularidad, tanto por la carta a Chanut que hemos citado anteriormente como por la admisión, un tanto fingida frente a sus interlocutores, de que solía dedicarle unas pocas horas al año a las cosas puramente intelectuales (AT, VII, 17; ver III, 692-693 y 695; ver también I, 350, IV, 613, y V, 139 y 165). Sea como fuese, la contemplación a la cual llega el meditador en la Tercera Meditación podría parecer episódica. Aparentemente, se trataría de un rapto discreto de amor apasionado, mientras que el amor del que hablan los santos que hemos revisado es un estado, un modo de vida que la invade toda.

El amor de Dios de Santa Rosa informa la totalidad de su existencia y los raptos místicos o milagros que puedan asociarse con él son efectos, digamos, periféricos. Se trata de un amor que se funda

35 Las dos frases citadas incluyen atributos añadidos en la versión francesa y por ello hago referencia tanto al texto latino como al francés. 
en disposiciones, hábitos y virtudes y se ejerce, idealmente, en todo momento, toda acción, todo pensamiento, todo deseo. Como es un amor sobrenatural, requiere de la gracia divina y de una disciplina corporal especial e intensa. Al mismo tiempo, es un amor que se despliega en el mundo, y que ve a Dios en todas sus criaturas.

Aunque el meditador debe separar su intelecto de su cuerpo y debe considerar su voluntad y sus acciones, la providencia divina y el orden de las cosas creadas, parece que se trataría de un ejercicio contenido (para lo primero, ver AT, IV, 608-612 y VII, 54-62). O al menos eso es lo que se desprende de la letra del texto de las Meditaciones y de los comentarios posteriores de Descartes.

Tocamos aquí el meollo del asunto. Veamos.

Dejemos sentado, en primer lugar, que Descartes no confunde un rapto apasionado, tal vez intensísimo pero siempre discreto y pasajero, con un estado anímico estable y duradero. Compara el amor de Dios con la amistad y con el amor al soberano y a la patria, ninguno de los cuales se puede propiamente reducir a un arrebato efímero (ver AT, IV, 611-613). Y describe sus resultados de manera que confirman que el verdadero amor requiere disposiciones anímicas firmes: quien ama a Dios «no desea nada..., salvo que se haga su voluntad. Como sabe que nada sucede sin que Dios no lo haya decretado, ya no teme la muerte, ni los dolores ni las desgracias.... [Y]a no evita los males y las aflicciones... y menos todavía los bienes o placeres lícitos... y... su amor lo hace perfectamente feliz» (AT, IV, 609).

La peculiaridad cartesiana, entonces, no parece estar tanto en el final del camino sino en el camino mismo. Y esto corresponde a una diferencia en la concepción del ser humano. Recordemos que, para llegar a Dios, santa Teresa insiste en la necesidad de amar más que de pensar, puesto que «el alma no es el pensamiento ni la voluntad es mandada por él» (2012: 688). ${ }^{36}$ En esto, como hemos visto, no

36 Aunque esctíctamente en este pasaje santa Teresa esté pensando en la meditación imaginativa, la frase se puede extender al discurso intelectual y el entendimiento, particularmente en el contexto presente. 
difiere ni de san Juan ni de san Francisco de Sales. Para todos ellos el camino a Dios es a través de la voluntad. La meditación imaginativa y el entendimiento pueden ayudar, pero por sí no bastan. Es la voluntad regida por el amor a Dios la que supera el pecado y somete e ilumina a la mente y al intelecto.

Por el contrario, Descartes sostiene que el intelecto, al percibir clara y distintamente la verdad o el bien, somete a la voluntad (ver AT, VII, 57-60). Es decir, frente a una verdad evidente no es posible suprimir el juicio o afirmación de su verdad, al igual que no es posible que la voluntad resista actuar de acuerdo a lo que percibe evidentemente como bueno. Es por ello que el itinerario cartesiano al amor de Dios consiste en llevar al entendimiento a la percepción de la idea de Dios, sabiendo que solo a través de una idea adecuada de Él es posible demostrar su existencia y que la adecuada percepción de esa idea de un ser infinito y por consiguiente necesario lo llevará a la contemplación de Dios mismo. Y a su vez esa percepción es posible solamente si el entendimiento puede ejercitarse liberado de la interferencia sensorial. El camino cartesiano no se centra en el ordenamiento de la voluntad, de los apetitos y deseos, sino en la liberación de la percepción intelectual, que irá descubriendo sus objetos próximos, primero su alma y luego llevado por las necesidades argumentales, Dios. Conforme los percibe mejor, tanto con mayor claridad como más completos, su voluntad se ve doblegada por el bien y la verdad de estos objetos. A Descartes, pareciera que, antes que los vicios y apetitos del meditador, le preocupan sus prejuicios y falsas creencias.

Esta doctrina de raigambre socrática de que la voluntad no puede resistirse frente al entendimiento de la verdad y el bien motivó una crítica de Arnauld. Aunque Descartes distingue entre la percepción natural y la gracia de la iluminación sobrenatural, en la Cuarta Meditación sostiene que «la fuente del error y el pecado» se encuentra en la voluntad que actúa cuando el intelecto no percibe con claridad y distinción (AT, VII, 58; ver también, por ejemplo, AT, VII, 147-149). 
Arnauld reaccionó con «extrema ansiedad» frente a las implicaciones de esta posición y, citando a san Agustín, le pidió a Descartes que «deje en claro dos cosas» (AT, VII, 215; ver 216-217).

La primera es que las Meditaciones se ocupan «sobre todo de los errores que cometemos al distinguir entre lo verdadero y lo falso y no aquellos que ocurren cuando buscamos el bien». La segunda es que

cuando afirma que debemos asentir solamente frente a lo que conocemos clara y distintamente, está tratando solamente de asuntos que tienen que ver con las ciencias y la contemplación intelectual, y no con las cosas de la fe y la conducción de nuestras vidas, y que por consiguiente sus advertencias se aplican solo a las opiniones adoptadas impulsivamente por los prejuiciosos y dogmáticos, y no a la fe prudente de los creyentes (AT, VII: 216).

Es fácil imaginar la respuesta cartesiana frente a una parte del segundo punto, aquella que tiene que ver con la fe y la gracia. En la Cuarta Meditación, incluso, el meditador distingue entre la gracia sobrenatural y el entendimiento natural y considera cómo ambos pueden determinar la voluntad: «ni la gracia divina ni el conocimiento natural disminuyen jamás mi libertad» (AT, VII, 58). Las Meditaciones no niegan ni limitan la fe. El matiz, como veremos, tiene que ver con la «conducción de nuestras vidas». Descartes nunca adoptó el primer consejo, ni podría haberlo hecho sin abandonar una doctrina que está en el centro mismo de su concepción de la meditación metafísica, como estamos viendo.

La ansiedad de Arnauld tenía fundamento. Ya años antes, en 1637, su fiel amigo y corresponsal Marin Mersenne (1588-1648) había detectado el problema. Descartes responde que «el bienestar del que hablo no puede entenderse en un sentido teológico, que involucre la gracia, sino solamente en un sentido filosófico moral y natural, donde no se considera en absoluto la gracia, de manera que no se me puede acusar del error de los seguidores de Pelagio» (AT, I, 366). El error que Descartes dice evitar, la herejía pelagiana, es 
sostener que sin la gracia divina y por medios puramente humanos y naturales podemos evitar el pecado y alcanzar la salvación.

En 1642, Descartes vuelve sobre el tema en otra carta a Mersenne. Luego de recalcar su fe católica y la profesión de ella que ha hecho repetidas veces, escribe que «también [ha] buscado los errores de Pelagio para saber en qué se pueden fundar aquellos que dicen que comparto su opinión, la que yo no conocía antes» (AT, III, 544.) Es difícil interpretar el final de esta frase: tal vez había olvidado el intercambio anterior; tal vez quiere decir que no conocía las opiniones imputadas a Pelagio mismo sino solo las de sus seguidores; tal vez, para mí lo más probable, se refiera a la formulación precisa de la herejía, mientras que en la carta anterior hablaba en un sentido general. Sea como fuese, dice considerar la acusación «poco creíble y tomada de los pelos». A continuación se explica:

Pelagio dijo que se pueden hacer buenas obras y merecer la vida eterna sin la gracia, lo que la Iglesia ha condenado; y yo he dicho que podemos conocer que Dios existe por la razón natural, pero al afirmarlo no he dicho que este conocimiento amerite de sí y sin la gracia la gloria sobrenatural que esperamos en el cielo. Ya que, por el contrario, es evidente que, siendo sobrenatural esta gloria, se requieren fuerzas más que naturales para merecerla. Y yo no he dicho nada sobre el conocimiento de Dios que no digan también todos los teólogos. Pero hay que recalcar que lo que conocemos por la vía natural, como que es todo bueno, todopoderoso, todo verdad, etc. puede ser muy útil para preparar a los infieles a recibir la fe, aunque no baste para que se ganen el cielo, puesto que para eso es necesario creer en Jesucristo y otras cosas reveladas que dependen de la gracia (AT, III: 544).

Descartes confunde con esta respuesta. El problema no es el conocimiento de Dios, aunque sea cierto que, culminando una tradición filosófica que viene de san Anselmo y pasa por Duns Scoto, él haya mostrado que para probar la existencia de Dios es necesario antes explorar su naturaleza al menos tanto como para percibir su 
posibilidad y su necesidad. ${ }^{37} \mathrm{El}$ problema es el amor de Dios y tanto el camino para llegar a la contemplación de Dios mismo en que se funda ese amor como sus consecuencias para «la conducción de la vida». Descartes se aparta de dos tesis tradicionales en la tradición teológica al sostener que por medios enteramente humanos podemos llegar al amor de Dios y que la percepción natural del bien permite evitar el pecado.

En la carta a Chanut, Descartes sí enfrenta el problema: «Yo no afirmo en absoluto que este amor sea meritorio sin la gracia; dejo para los teólogos aclarar eso. Pero me atrevo a decir que en esta vida es la pasión más placentera y útil que podemos tener, y que hasta puede ser la más fuerte, aunque para ello haya necesidad de una meditación muy concentrada dado que constantemente nos distrae la presencia de otros objetos» (AT, VII, 608.) Es claro que aunque no menciona a Pelagio y su herejía, es a eso a lo que se refiere. Veamos si en verdad Descartes tiene derecho a esta respuesta.

Desde la perspectiva del camino hacia el amor de Dios, aunque el meditador se concentra en superar sus prejuicios sensoriales e ir limpiando su mente de las creencias que ha ido adquiriendo desde niño, es lícito preguntarse por su relación con sus apetitos e inclinaciones corporales. La división literaria de las Meditaciones en seis días no corresponde a la realidad meditativa. Hemos visto que Descartes le pide a sus lectores detenerse al menos meses en la primera meditación y semanas en la segunda. La finalidad es superar la confianza en los sentidos para apartar al alma del cuerpo. Es claro que este no es un ejercicio meramente cognitivo y que mucho de la interferencia de esos «otros objetos» viene no de opiniones y creencias sino de los inevitables apetitos del cuerpo, la necesidad de comer y dormir, la incómoda o placentera presencia del cuerpo son obstáculos que enfrenta la percepción de Dios y el alma.

37 Ver Secada (2000: capítulo 6 y 230-235). 
Justamente, las disciplinas de santa Rosa -sus ayunos, acostumbrarse a dormir sobre una cruz, usar cilicio, corona de espinas y toscas prendas interiores- lejos de sumir al alma en el cuerpo son las formas en que logra dejarlo atrás y acercarse a Dios. Sin semejantes prácticas, sumido en sus apetitos como cualquier ser humano, es difícil imaginar que el meditador cartesiano logre «preparar su alma para la consideración de las cosas del intelecto y ayudarla a distinguirlas de las cosas corporales» (AT, VII, 171-172). Descartes reconoce que el alma de los niños «está tan capturada dentro del cuerpo que los únicos pensamientos que tiene son los que resultan de la manera en que se afecta el cuerpo» (AT, V, 149-150). Incluso de adultos «el cuerpo obstruye al alma... [C] uando nos pinchamos con una aguja... no podemos pensar en otra cosa» (AT, V, 150). El meditador debe desarrollar hábitos que le permitan superar la inevitable presencia de su cuerpo. No es casual, sugiero, que Descartes mismo haya abandonado el mundo y haya vivido en reclusión casi monacal desde que decidió, en 1629 e impulsado por Bérulle, emprender el proyecto que culminaría en las Meditaciones.

Pero también necesita otras disciplinas. Las usuales virtudes cognitivas, como la concentración y la tenacidad son candidatos evidentes. Pero, ¿no debe superar también, por ejemplo, su vanidad y su soberbia? Varias veces en el curso de las Meditaciones el meditador debe reconocer sus limitaciones y su finitud. Más aun, no es claro que pueda emprender el ejercicio meditativo mismo si no reconoce sus errores y si no está dispuesto a someterse a las exigencias que le impone su guía. Tal vez Descartes pensaba que el intelecto suficientemente fuerte y dispuesto doblegaría la voluntad frente al error patente, o al probable error una vez pactado el método escéptico. Igual, el punto final es que aun así al hacerlo estaría desarrollando virtudes.

La ausencia notable en este camino, notable por el contraste con la tradición de espiritualidad cristiana, es el amor. Descartes puede argumentar que el intelecto somete a la voluntad, pero ahora estamos considerando el camino que lleva al correcto uso del 
intelecto, camino que se verá interrumpido por una voluntad desordenada. Santa Teresa, san Juan y san Francisco hablan desde la experiencia de la vida humana cuando reconocen que la voluntad pecaminosa oscurece el entendimiento. Ignorarla, como la ignora Descartes al callar frente a este aspecto del meditador, es ocultar un aspecto de quien inicia las reflexiones meditativas puesto que no es creíble que no reconociera que no es buen candidato para el ejercicio cartesiano quien esté lleno de sí mismo, corrompido por el orgullo y el egoísmo, o por otros vicios del cuerpo como la gula o la lujuria. Difícilmente cuestionará sus convicciones al punto que requiere Descartes quien no posea una buena dosis de humildad.

De paso notemos que no cabe objetar aquí que Descartes mismo no parece haber estado poseído por esta virtud y que repetidamente en su vida mostró una excesiva soberbia. El resultado de semejante objeción sería entonces sencillamente reconocer que las raíces de su error, al no considerar este aspecto del camino meditativo, se encontraban en su personalidad.

Pasemos a los efectos de la meditación exitosa. Hemos visto ya que Descartes mismo reconoce que lleva al meditador a enfrentar las vicisitudes de la fortuna, los dolores y sufrimientos al igual que los triunfos y placeres, con moderación y verdadera alegría. La descripción de quien ha llegado al amor de Dios por la vía natural, que hemos citado anteriormente, es la de alguien que sabe conducir bien su vida, al menos en buena medida. Quien llega por la vía natural al amor de Dios comparte demasiado con quien ha entrado a la séptima morada de Santa Teresa, quien «temor ninguno tiene de la muerte» y más bien es «extremo el deseo que queda en [él] de que se haga la voluntad de Dios» (2012: 575, 574-575). Nuevamente, es difícil imaginar al meditador cartesiano exitoso como alguien poseído por la ira o la lujuria o la gula o la pereza.

El meditador cartesiano exitoso, entonces, se parece bastante más a santa Rosa que lo que podríamos colegir de la respuesta de Descartes frente a la acusación pelagiana. Es más, insistir en ella 
parece transportarlo de esa herejía a otra igualmente cercana, la predestinación calvinista. Un Dios que condene al meditador está demasiado cerca del que condenaría a santa Rosa.

\section{A Modo de CONCLUSIón}

Consideremos el asunto desde otro punto de vista. La doctrina platónica de Descartes incluye las siguientes tesis:

1) el conocimiento y la comprensión filosófica suponen percepciones puramente intelectuales y no sensoriales (aunque Descartes enfatiza la similitud entre estos actos de percepción y los actos discretos de percepción sensorial, también les reconoce una dimensión experiencial no discreta, por ejemplo en cuanto los identifica con la comprensión conceptual y con las correspondientes disposiciones, y les permite jugar un papel a través de la memoria; esta tesis se puede apoyar en consideraciones aristotélicas que muestran la necesidad de encontrar puntos de partida prístinos y fundados para toda argumentación, so pena de reducir el conocimiento, en ultimísima instancia, a un asunto de mera opinión);

2) los objetos de estas percepciones no son corporales sino espirituales, y algunos no son naturales sino trascendentes (aunque el alma es natural, no es física y Dios es el fundamento sobrenatural del orden natural; no es casual que la contemplación del meditador al final de la Tercera Meditación sea, en esta vida, un anticipo, muy remoto y sumamente imperfecto pero anticipo al fin, de la visión de las almas bienaventuradas; esta tesis se puede apoyar en las consideraciones platónicas que llevan a postular propiedades o arquetipos eternos y no sujetos a los avatares e imprecisiones del mundo físico y empírico); 
3) para llegar a tener estas percepciones es necesario someterse a disciplinas y desarrollar virtudes que no son puramente epistémicas, como la atención o la agudeza mental, sino también de carácter y no solamente por razones instrumentales, sino para dirigir el intelecto hacia sus objetos propios (aquí pueden convergir estas disciplinas espirituales con las prácticas religiosas; el fundamento de esta tesis requiere reconocer tanto la sabiduría como fin propio de la filosofía, como el lugar de esta sabiduría filosófica en la conducción de la vida humana);

4) el contenido de estas percepciones o experiencias no es discursivo ni puede capturarse discursivamente, tanto porque es inagotable como porque el lenguaje no le hace justicia (este es un punto que hemos mencionado pero que no hemos desarrollado aunque está presente en la obra de Descartes; ver, por ejemplo, AT, VIII-1, 8-9 y X, 523-524; ver también los múltiples pasajes donde apela a la intuición para explicar un objeto simple, como en AT, II, 597; VII, 20; X 425-427).

La última tesis abre una alternativa. Puede sostenerse, con Aristóteles y sus seguidores escolásticos a quienes Descartes sigue en este punto, que la experiencia intelectual establece contenidos proposicionales discursivos que son el punto de partida de las deducciones y argumentos y que pueden constituir una doctrina definitiva. Las Disputaciones metafísicas de Francisco Suárez (15481617) ejemplifican el cuidado con el que la escolástica tardía afirma sus conclusiones doctrinales, consciente de su carácter tentativo y abierto a cuestionamiento, sin abandonar, sin embargo, el ideal de una resolución discursiva de los problemas metafísicos. Descartes sostendría que es el empirismo escolástico lo que corrompió sus intuiciones y por consiguiente las premisas básicas de sus argumentos deductivos, y les impidió resolver los problemas filosóficos de manera estable y definitiva. 
Puede también sostenerse, por el contrario, que ningún contenido discursivo es acabado y definitivo (salvo tal vez en matemáticas y otros formalismos semejantes, cuyo carácter como lenguajes es discutible), sea porque es siempre expandible o matizable, sea porque no logra representar la realidad sin distorsionarla. Todo discurso se mantendría, es contextual y está al servicio de traer a mente experiencias que lo rebasan. Esta posición no está obligada a negar la existencia de verdades o falsedades absolutas, aunque las sitúe en contextos y usos específicos. Ni tampoco tiene por qué negar la relación esencial que hay entre la práctica filosófica y la argumentación racional y discursiva. Lo único que niega es que haya un discurso filosófico acabado y definitivo. ${ }^{38}$

Este último punto puede iluminar la estructura de la historia de la filosofía y ayudar a entender cómo así hay progreso en ella aunque se vuelva siempre sobre el mismo punto. En esto solamente ampliaría una consecuencia de la posición cartesiana, extendiendo el alcance de la práctica meditativa y sometiendo las formulaciones doctrinales discursivas a su dialéctica inagotable. Sabemos que a pesar de creer que había establecido una doctrina metafísica sólida y definitiva, Descartes también pensaba que la contemplación de los objetos propios del intelecto, Dios y el alma, era una práctica inagotable, enriquecedora y eminentemente filosófica o metafísica.

Esta lección cartesiana, no obstante, se enriquece con la comparación entre el meditador y la santa limeña, apartada como estuvo ella completamente del razonamiento y el discurso, al revelar un ámbito de reflexión que relaciona la filosofía con la vida, el lenguaje con la memoria y la experiencia, la comprensión con el deseo y el entendimiento con el amor, relaciones que el intelectualismo y la prudencia de Descartes impidieron que explorase explícita y abiertamente. Y aquí, como siempre, encontraremos que la verda-

38 El lector puede encontrar en estas consideraciones un eco de doctrinas platónicas; ver Platón (2010). 
dera oposición a Platón en filosofía no viene de Aristóteles, sino de Demócrito o Epicuro (y en tiempos recientes Nietzsche, Quine o Rorty), y que en Descartes se encuentra no tanto el nacimiento de la modernidad (que más le debe a Hume y Kant que a él) sino la última formulación plena de esa primera opción. ${ }^{39}$

\section{REFERENCIAS}

BÉRulle, Pierre de

1989 «Discourse on the State and Grandeurs of Jesus». En: Bérulle and the French School. Selected Writings. Edición de William M. Thompson. Traducción de Lowell M Glendon, S.S. Nueva York: Paulist Press, pp. 109-171.

39 Estoy en deuda con el público en diversos foros en los que he presentado algunos aspectos de los temas de este ensayo, en octubre de 2011 en el XIII Congreso Nacional de Filosofía en Iquitos y en la Universidad Nacional Federico Villareal en Lima; en febrero de 2015 en la Universidad de Bohemia del Sur en Budweis y en la Academia de Ciencias de la República Checa en Praga; en el Simposio sobre Descartes y la ilustración en el Instituto Tecnológico de Massachusetts (MIT) en mayo de 2015; en la conferencia anual de la Asociación Filosófica de Virginia (VPA) en octubre de 2016; en noviembre de 2016 en el SUNY College en Postdam; en agosto de 2017 en el XVI Congreso Nacional de Filosofía en la Universidad Nacional San Cristóbal de Huamanga en Ayacucho y en el XIII Simposio de Estudiantes de Filosofía en la Pontificia Universidad Católica del Perú; y en octubre de 2017 en el Departamento de Filosofía de la Universidad de Arizona en Tucson. Sus preguntas y comentarios me han ayudado a evitar errores y desaciertos, y me obligaron a afinar y desarrollar mis ideas. Similar deuda tengo con mis alumnos, tanto en mi hogar académico, la Universidad de Virginia, como durante las temporadas en que enseñé en la Pontificia Universidad Católica del Perú entre 2013 y 2016. Finalmente, debo reconocer que no hubiese podido articular nada de lo que he propuesto aquí sin las muchas conversaciones que he tenido sobre estos y otros temas afines durante muchos años con Ivy Arbulú Wiener y también con Tal Brewer, James Cargile, Roque Carrión Wam, Fernando Carvallo Rey, John Marshall, Francisco Tumi Guzmán y María Alejandra Valdez Orezzoli. 
Biblia de JerusaléN

1998 Biblia de Jerusalén. Bilbao: Desclée de Brouwer.

Borriello, Luigi, et al.

2002 Diccionario de mistica. Madrid: San Pablo.

BREWER, Tal

2009 The Retrieval of Ethics. Nueva York: Oxford University Press.

Carrasco Ligarda, Rosa

2016 Santa Rosa de Lima. Escritos de la santa limeña. Lima: Facultad de Teología Pontificia y Civil de Lima, Provincia de Santa Rosa y Sociedad de San Pablo.

Del Busto Duthurburu, José Antonio

2006 Santa Rosa de Lima. Lima: Pontificia Universidad Católica del Perú.

DESCARTES

1996 Oeuvres philosophiques de Descartes. Edición de Charles Adam y Paul Tannery. París: J. Vrin.

2013 Lettres sur l'amour. Edición y selección de Denis Kambouchner. París: Éditions Mille et Une Nuits.

Flores ArÁoz, José, et al.

1995 Santa Rosa de Lima y su tiempo. Lima: Banco de Crédito.

García-Hernández, Benjamín

1997 Descartes y Plauto. Madrid: Tecnos.

GraZiano, Frank

2004 Wounds of Love: The Mystical Marriage of Saint Rose of Lima. Nueva York: Oxford University Press.

McGinn, Bernard

2017 Mysticism in the Golden Age of Spain. Parte 2 del volúmen 6 de The presence of God. A History of Western Christian Mysticism. Nueva York: Crossroads Publishing Company. 
Mujica, Ramón

2005 Rosa limensis. Mistica, politica e iconografía en torno a la patrona de América. México: IFEA; CEMCA y FCE.

Myers, Kathleen Ann

2003 «Reedemer of America': Rose of Lima (1586-1617), the Dynamics of Identity, and Canonization». En: Allan Greer y Jodi Bilinkoff (eds). Colonial Saints: Discovering the Holy in the Americas. Nueva York: Routledge, pp. 251-275.

PANNIKAR, Raimon

2015a Mistica, plenitude de Vida. Barcelona: Herder.

2015b Espiritualidad, el camino de la Vida. Barcelona: Herder.

PARMÉNIDES

1965 Parmenides. A text with translation, commentary and critical essays. Edición y traducción de Leonardo Taran. Princeton: Princeton University Press.

2007 Poema. Fragmentos y tradición textual. Edición bilingüe y traducción de Alberto Bernabé. Madrid: Istmo.

2011 Parmenides of Elea. Fragments. En Richard D. McKirahan. Philosophy before Socrates. Indianapolis: Hackett Publishing, pp. 145-150.

Platón

2010 Fedro. Edición bilingüe y traducción de Armando Poratti. Madrid: Akal.

Saint François de SaLES

1819 Introduction a la vie dévote. París; Lyon: Méquignon Fils Ainé y Périsse Frères.

San Buenaventura

2010 Itinerario de la mente a Dios. En: Obras, vol. 1. Madrid: Biblioteca de Autores Cristianos.

San Francisco de Asís

2006 Escritos. Biografias. Documentos de la época. Madrid: Biblioteca de Autores Cristianos. 
San Francisco de SALES

2010-2016 Obras selectas. 2 vols. Madrid: Biblioteca de Autores Cristianos.

SAN JUAN DE La Cruz

2009 Obras completas. Madrid: Biblioteca de Autores Cristianos.

Santa Teresa de Jesús

2012 Obras completas. Madrid: Biblioteca de Autores Cristianos.

SECADA, Jorge

2000 Cartesian Metaphysics. The Late Scholastic Origins of Modern Philosophy. Cambridge: Cambridge University Press.

2013 «God and Meditation in Descartes»s Meditations». En: Karen Detlefsen (ed.). Descartes' Meditations: A Critical Guide. Nueva York: Cambridge University Press, pp. 200-225.

2021 «Descartes and the Scholastic and Meditative Traditions». En: Jorge Secada y Cecilia We (eds.). The Cartesian Mind. Londres: Routledge. (De próxima publicación.)

Thompson, William M.

1989 «An Introduction to the French School». En: Bérulle and the French School. Selected Writings. Nueva York: Paulist Press, pp. 1-101.

UnDERHILL, Evelyn

2006 La Mística. Estudio de la naturaleza y desarrollo de la conciencia espiritual. Madrid: Editorial Trotta. 